\title{
РТ-параметры многостадийной эволюции пород Мейерского надвига в юго-восточном окончании Раахе-Ладожской зоны (Северное Приладожье)
}

\author{
Вивдич Э.С. ${ }^{1}$, Балтыбаев Ш.К. ${ }^{2,3}$, Галанкина О.Л. ${ }^{3}$ \\ 1,2 Санкт-Петербургский горный университет, Санкт-Петербург, emily.vivdich@yandex.ru; \\ shauket@mail.ru \\ ${ }^{3}$ Институт геологии и геохронологии докембрия РАН, Санкт-Петербург
}

Аннотация. Результаты геотермобарометрии выявляют полистадийность формирования пород Мейерской надвиговой зоны в Северном Приладожье, по которой сочленяются комплексы палеопротерозойского Свекофеннского пояса и окраины архейского Карельского кратона. РТ-тренд эволюции пород аллохтонного и автохтонного блоков вблизи шовной зоны характеризуется компрессионным трендом на начальной стадии развития надвига, который сменяется трендом спада давления, сопряженно с температурой. Давления, достигающие 8 кбар и выше, возникали, вероятно, за счет дополнительной тектонической нагрузки в условиях тангенциального сжатия при надвигании пород аллохтонного блока на автохтонный.

Ключевые слова: РТ-тренд, геотермобарометрия, надвиг, гранаты, парагенезисы, стадийность.

\section{PT-parameters of polystage evolution of the rocks of the Maeyeri thrust zone in the southeastern end of the Raahe-Ladoga zone (Northern Ladoga)}

\author{
Vivdich E.S. ${ }^{1}$, Baltybaev S.K. ${ }^{2,3}$, Galankina O.L. ${ }^{3}$ \\ ${ }^{1}$ Saint-Petersburg Mining University,St.-Petersburg,emily.vivdich@yandex.ru; shauket@mail.ru \\ ${ }^{3}$ Institute of Precambrian geology and geochronology RAS, St.-Petersburg
}

Annotation. The results of geothermobarometry are revealed the polystage formation of the rocks of the Meyeri thrust zone in the Northern Ladoga area, along which the complexes of the Paleoprotorozoic Svecofennian belt and of the Archean Karelian craton are joined. The PT-path of the evolution of the rocks near the suture zone is characterized by a compression pattern at the initial stage, which is then replaced by the trend of the pressure decreasing together with the temperature. Pressures reaching $8 \mathrm{kbar}$ and above occurred probably due to an additional tectonic load under conditions of the tangent compression events during overthrusting of the rocks of the allochthone block onto the autochthonic ones.

Key words: PT-path, geothermobarometry, thrust, garnet, paragenesiss, stages.

\section{Введение}

На территории Северного Приладожья сочленяются толщи палеопротерозойского Свекофеннского подвижного пояса (СПП) и архейского Карельского кратона (КК). Область сочленения представляет систему надвигов - Мейерскую надвиговую зону (МНЗ) (Балтыбаев и др., 1996; 2000). Геотермобарометрия гранат-биотитовых (Grt-Bt) и гранат-двуслюдяных (Grt-Bt-Ms) гнейсов из МН3 позволила определить стадийность в развитии пород и, соответственно, надвига. Выявлен более низкобарический режим образования мусковитовых парагенезисов (1-2 кбар) по сравнению с безмусковитовыми - биотитовыми парагенезисами (2-5 кбар) для интервала температур от $\sim 500$ до $\sim 650^{\circ} \mathrm{C}$. Эти оценки были получены исключительно по метапелитовым минеральным парагенезисам. В данной работе предлагаются результаты термобарометрического изучения гнейсов МНЗ, содержащих, в частности, высококальциевые (амфиболовые) минеральные парагенезисы. Используются также новые образцы, содержащие Grt-Bt парагенезисы, для большего охвата площади развития МН3.

\section{Краткая характеристика МНЗ}

Мейерская надвиговая зона прослежена в субширотном направлении на 40 км при ширине 20 км и мощности 6-8 км (рис. 1). Структурной особенностью МНЗ является пологое залегание 
метаморфической полосчатости, сланцеватости и линейности. Морфология и структурные элементы тел позволяют определить систему пологих нарушений, по которым сильно метаморфизованные и мигматизированные породы СПП надвинуты на относительно слабометаморфизованные AR-PR породы окраины КК. Плоскость сместителя МНЗ в современных координатах имеет субширотное простирание и пологое $\left(20-30^{\circ}\right)$ падение на юг. Ориентировка линейности отражает субмеридиональное растяжение пород во время тектонического движения.
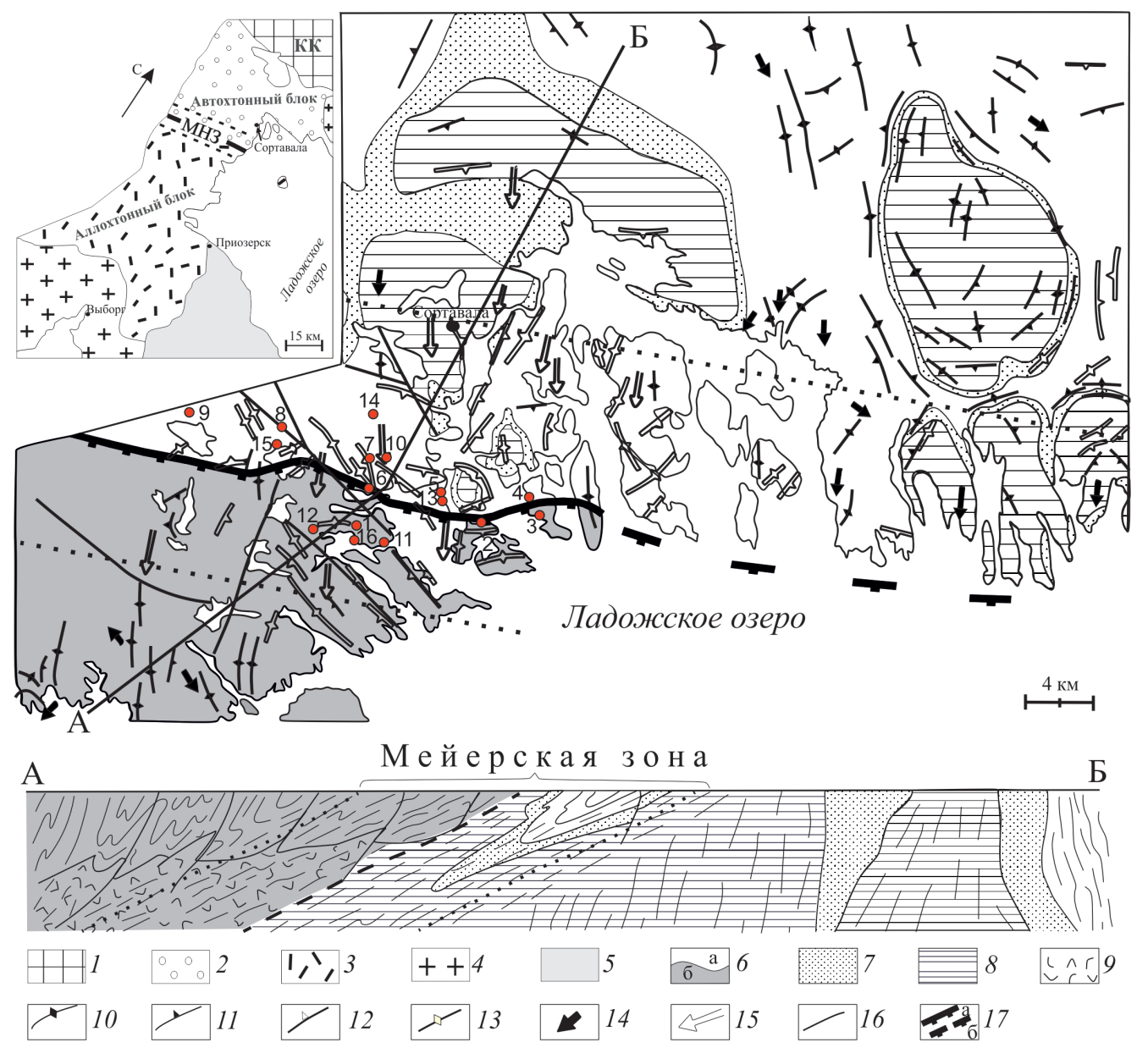

Рис. 1. Схема строения пород Северного Приладожья и разрез через МНЗ (Балтыбаев, Вивдич, 2021). 1 - архейский фундамент; 2, 3 - палеопротерозойские сланцы и гнейсы; 4 - рапакиви; 5 -рифейские породы; 6 ладожская серия: метаалевролиты, метапесчаники, их метаморфизованные аналоги (гнейсы) и гранитоиды: a - породы Северного домена, б - Южного; 7 - сортавальская серия: амфиболиты; 8 - AR гранито-гнейсы; 9 - основные и ультраосновные породы; 10-13 - ориентировка сланцеватости: 10 - $\left(70-90^{\circ}\right), 11$ - $\left(50-70{ }^{\circ}\right)$, $12-\left(30-50^{\circ}\right), 13-\left(0-30^{\circ}\right) ; 14-15$ - ориентировка линейности: 14 - крутой (свыше $\left.40^{\circ}\right), 15$ - пологой (до 40 o); 16 - разломы; 17 - положение сместителя МНЗ: а - установленное, б - предполагаемое. Границы МНЗ показаны точечными линиями. Местоположения образцов: $1-2465 \mathrm{v} ; 2-5785 ; 3-5445 ; 4-5442 \mathrm{a} ; 5$ - 5267a; 6 - 996-1; 7 - 994-1; 8 - 2465b; 9 - 4098b; 10 - Б-20-425; 11 - Б-20-436; 12 - Б-20-450 (Б-20-450-1); 13 - Б-20$455-2 ; 14$ - Б-20-458; 15 - Б-20-461; 16 - Б-20-466.

Fig. 1. Structural map of the Northern Ladoga and a section of the Meyeri thrust zone (Baltybaev, Vivdich, 2021). 1 - Archaean basement; 2, 3 - Paleoproterozoic schists and gneisses; 4 -rapakivi; 5 - Riphean rocks; 6 - Ladoga group: metaaleurolites, metasandstones, and metamorphosed analogs (gneisses) and granitoids: a - rocks of the Northern domain, $\mathrm{b}$ - Southern domain; 7 - Sortavala group: amphibolites; 8 - Archean granite-gneisses; 9 - basic and ultrabasic rocks; $10-13$ - orientation of the schistosity: $10-\left(70-90^{\circ}\right), 11-\left(50-70^{\circ}\right), 12-\left(30-50^{\circ}\right), 13-\left(0-30^{\circ}\right)$; 14-15 - orientation of the linearity: 14 - steep (over $40^{\circ}$ ), 15 - slanting (up to $40^{\circ}$ ); 16 - faults; 17 - a suture of the MTZ: $a$ - fixed, $b$ - expected. Dotted lines are the boundaries of the MTZ. The samples: $1-2465 \mathrm{v} ; 2-5785$; 3-5445; 4-5442a; 5-5267a; 6-996-1; 7 - 994-1; 8-2465b; 9-4098b; 10-Б-20-425; 11 - Б-20-436; 12 - Б-20-450 (Б-20-450-1); 13 - Б-20-455-2; 14 - Б-20-458; 15 - Б-20-461; 16 - Б-20-466. 
Для геотермобарометрии выбирались различные по составу метаморфические и метаинтрузивные породы с предпочтением Grt-содержащих как более пригодных для PT-метрии. Из более 300 образцов для термобарометрии отобрано 16 (рис. 1.)

\section{Характеристика пород и термобарометрических инструментов}

В аллохтонном (южная часть) и автохтонном (северная часть) блоках МНЗ широко распространены гнейсы с Grt-Bt и Grt-Bt-Ms парагенезисами. С ними встречаются кварц и плагиоклаз, иногда калиевый полевой шпат, кордиерит, силлиманит, амфиболы, хлорит и ряд других минералов. В аллохтонном блоке практически все породы превращены в полосчатые, сетчатые мигматиты с разным соотношением фельзических и мафических минералов. В автохтонном - мигматизация слабая.

В соответствии с минеральными парагенезисами подбирались петрологические инструменты для термо- и барометрии. Наличие граната, биотита, мусковита, плагиоклаза и кварца позволило использовать взаимосогласованные геотеромобарометры: гранат-биотитовый (Gt-Bt термометр; Holdaway, 2000), гранат-биотит-плагиоклаз-кварцевый (GBPQ барометр; Wu et al., 2004) и гранат-биотит-мусковит-плагиоклазовый (GBMP барометр; Wu, 2014). Минеральные парагенезисы в породах повышенной известковистости, отличаются от вышеописанных. В частности, гранатамфибол-биотит-плагиоклазовый гнейс (образец Б-20-450) содержит биотит, гранат, роговую обманку, плагиоклаз, кварц, ильменит, апатит. Гранат в нем гроссуляр-альмандиновый: гроссуляра до 19 \% против 2-5 \% в других породах. Биотит титанистый и, по сравнению с другими биотитами, низкоглиноземистый. Также характерен более основной плагиоклаз (от 46 до 56 \% An), в других породах - не выше 30-40 \% An. Наличие роговой обманки, плагиоклаза, граната позволяет применить гранат-амфиболовый термометр (Holland, Blundy, 1994).

Диапазоны составов всех минералов изученных пород не выходят за пределы составов, для которых производилась калибровка вышеуказанных термобарометров.

Сравнительные результаты минеральной геотермобарометрии приведены на рис. 2. В породе повышенной известковистости выявляются более высокие температуры и однозначно более высокие давления минералообразования. Давления 8 кбар и выше не характерны для окружающих пород, для которых они не превышают 5-6 кбар. Парагенезисы поздней стадии (Grt-Bt-Ms) выявляют спад давления от 5-6 кбар до 1-3 кбар при одновременном снижении температуры. Эти результаты согласуются с петрографическими наблюдениями, показывающими мусковит как наложенный минерал, формирующийся после биотита.

Кроме биминеральных термобарометров были рассчитаны мультиравновесные диаграммы на базе компьютерной программы TWEEQU (Berman, 1991). Некоторые результаты вычислений представлены на рис. 2 (б, г). Удовлетворительные пересечения не менее 3 независимых реакций могут быть указанием на достижение равновесия между минералами (и, соответственно, на применимость термобарометров, основанных на химических составах минералов).

В целом отмечается хорошая сходимость результатов при оценке РТ-параметров образования пород с использованием двух вышеуказанных методик термобарометрии пород.

\section{Выводы}

Новые данные позволяют выделить раннюю - более высокотемпературную и высокобарическую - стадию развития пород рассматриваемой тектонической структуры. Совокупно, в развитии пород МНЗ отчетливо выделяются 3 стадии: 1) повышенных давлений и температур, 2) умеренных давлений и температур, 3 ) низкобарическая и наиболее низкотемпературная. Эти стадии эволюции пород МНЗ находят выражение в смене составов минералов и/или появлении новых их парагенезисов.

Давление $\geq 8$ кбар превышает величину давления в окружающих породах и, скорее всего, возникло за счет дополнительной тектонической нагрузки в условиях тангенциального сжатия на ранней стадии надвигании пород СПП на породы окраины КК. 
(a)

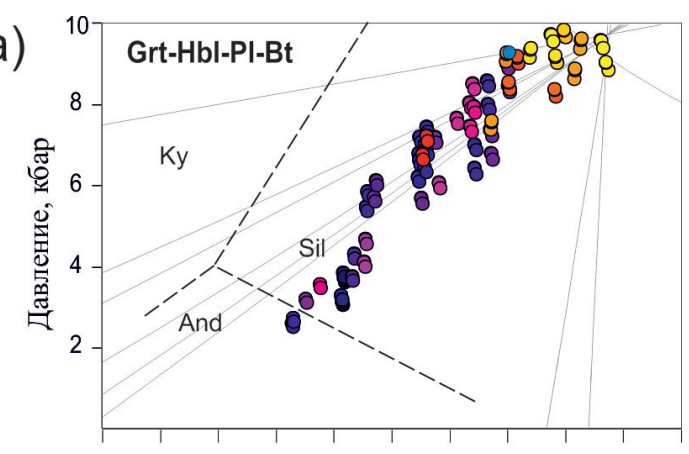

(B)

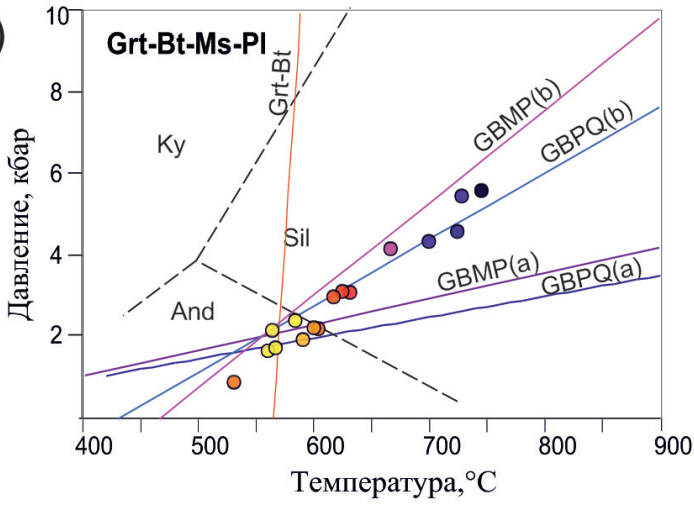

(д)

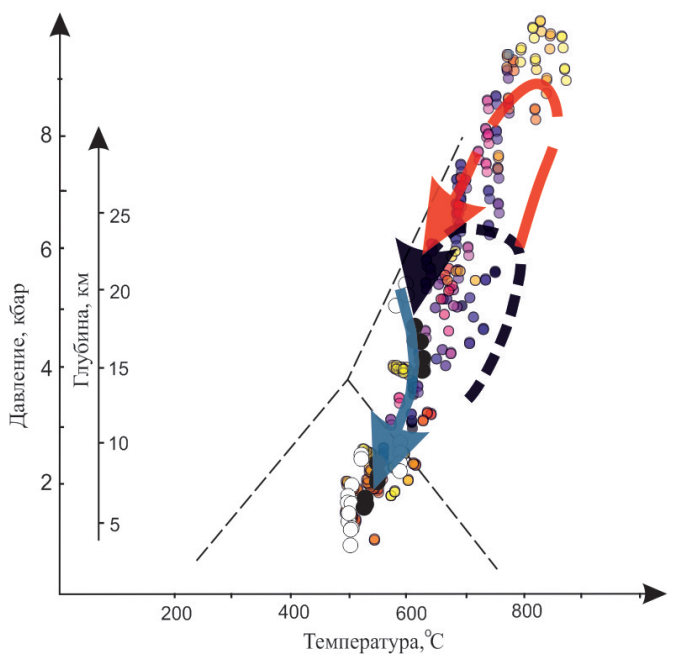

(б)

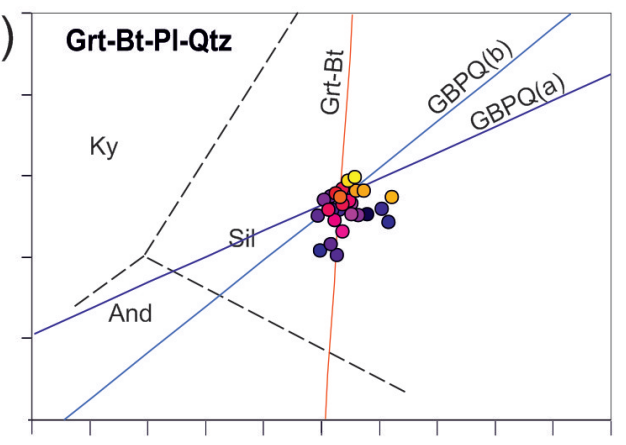

(г)

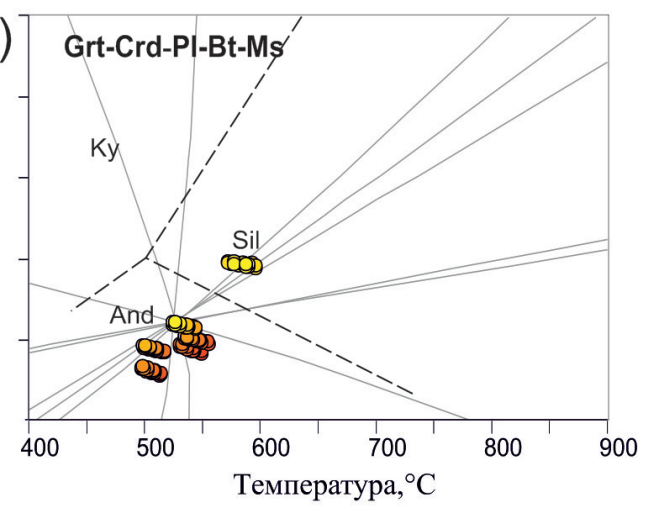

1

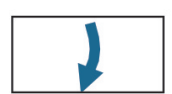

2

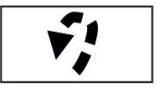

3

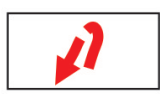

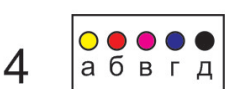

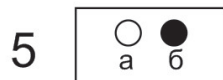

Рис. 2. РТ-оценки формирования пород МНЗ. (а) - гранат-амфибол-плагиоклаз-биотитовые парагенезисы; (б) - безмусковитовые (гранат-биотитовые); (в) - мусковитовые (гранат-двуслюдяные); (г) - гранат-кордиеритбиотит-плагиоклаз-мусковитовые; (д) - тренды развития пород МНЗ. 1 - тренд поздней стадии, 2 - в породах аллохтона на удалении от МНЗ, 3 - непосредственно в зоне стыка автохтона и аллохтона; 4 - точки пересечения линий минеральных реакций с различной степенью отклонения от равновесия: от наименьшего (а) до наибольшего (д); 5 - РТ-параметры пород автохтона (а) и аллохтона (б) на поздней стадии развития МНЗ.

Fig. 2. Estimated PT-parameters of the rocks of the MTZ. (a) - garnet-amphibole-plagioclase-biotite paragenesis; (b) - mouscovite-free (Grt-Bt); (c) - muscovite (Grt-two-mica); (d) - garnet-cordierite-biotite-plagioclase-muscovite; (e) - trends of the rocks of the MTZ. 1 - a trend of late stage, 2 - in an allochtone block at a distance from the MTZ; 3 - directly in the area of junction of autochtone and allochtone; 4 - crossing points of mineral reaction lines with varying degrees of equilibrium: from the smallest (a) to the greatest (d); 5 - PT parameters of autochtone (a) and allochtone (b) rocks at the late stage of MTZ's development.

Работа выполнена за счет финансирования темы НИР ИГГД РАН (№ 132-2019-0013) Минобрнауки России. 


\section{Литература}

1. Балтыбаев Ш.К., Глебовицкий В.А., Козырева И.В. и др. Геология и петрология свекофеннид Приладожья. СПб. Изд-во: СПбГУ. 2000. С. 200.

2. Балтыбаев Ш.К., Глебовицкий В.А., Козырева И.В. и др. Мейерский надвиг - главный элемент строения сутуры на границе Карельского кратона и Свекофеннского пояса в Приладожье, Балтийский щит // ДАН. 1996. Т. 348. № 3. С. 353-356.

3. Балтыбаев Ш.К., Вивдич Э.С. Эволюция Мейерской надвиговой зоны Северного Приладожья (Республика Карелия, Северо-Запад России): РТ-условия формирования минеральных парагенезисов и геодинамические реконструкции // Геотектоника. 2021. Т. 225. (в печати).

4. Вивдич Э.С., Балтыбаев Ш.К. Поздняя стадия развития Мейерской надвиговой зоны Северного Приладожья: реставрация РТ-условий по данным изучения минеральных парагенезисов и гранат-биотитовой(мусковит)-плагиоклаз-кварцевой геотермобарометрии // Актуальные проблемы геологии, геофизики и геоэкологии. Материалы XXXI молодёжной научной школы-конференции, посвящённой памяти членкорреспондента АН СССР К.О. Кратца (Санкт-Петербург, 5-9 октября 2020 г). Санкт-Петербург. 2020. C. 49-53.

5. Holdaway M.J. Application of new experimental and garnet Margules data to the garnet-biotite geothermometer // American Mineralogist. 2000. V. 85. P. 881-892.

6. Holdaway M.J. Recalibration of the GASP geobarometer in light of recent garnet and plagioclase activity models and versions of the garnet-biotite geothermometer // American Mineralogist. 2001. V. 86. P. 1117-1129.

7. Holland T., Blundy J. Non-ideal interactions in calcic amphiboles and their bearing on amphibole-plagioclase thermometry // Contributions to Mineralogy and Petrology. 1994. V. 116. P. 433-447.

8. Wu C.M. Revised empirical garnet-biotite-muscovite-plagioclase geobarometer in metapelites // Journal of Metamorphic Geology. 2015. V. 33. P. 167-176.

9. Wu C.M., Zhang J., Ren L.D. Empirical garnet-biotite-plagioclase-quartz (GBPQ) geobarometry in mediumto high-grade metapelites // Journal of Petrology. 2006. V. 45. № 9. P. 1907-1921. 